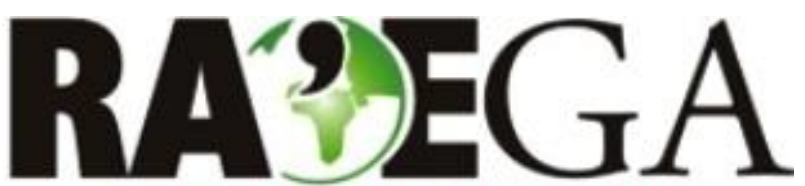

O ESPAÇO GEOGRÁFICO EM ANÁLISE

\title{
REFLEXÕES E TEORIAS SOBRE O LAZER - UM ROTEIRO PARA A GEOGRAFIA
}

\section{REFLECTIONS AND THEORIES ON LEISURE - A GUIDE FOR GEOGRAPHY}

\author{
Bruno José Rodrigues Frank \\ Universidade Estadual de Londrina \\ Londrina, PR, Brasil \\ e-mail:bruno.j.frank@gmail.com \\ Humberto Yamaki \\ Universidade Estadual de Londrina \\ Londrina, PR, Brasil \\ e-mail:yamaki@uel.br
}

\section{Recebido em: 28/04/2015}

Aceito em: 01/07/2016

\section{Resumo}

O lazer tornou-se uma necessidade humana, dotada de uma miríade de significados que são legíveis no espaço e no tempo. Trata-se de uma atividade social que consome e se desenvolve no espaço e para os indivíduos. Pretendemos abordar as principais semelhanças entre as abordagens de turismo, lazer e geografia, tanto no âmbito das teorias utilizadas como nos procedimentos e na natureza das pesquisas. O objetivo deste artigo é, a partir da síntese de algumas teorias envolvendo Lazer e Geografia e das contribuições de outras áreas, elaborar um roteiro com possíveis abordagens para o trato geográfico do tema. O referencial teórico é trabalhado à luz de alguns dos conceitos de geografia mais comuns, tais como lugar, paisagem e região, elencando para cada um, possibilidades de estudo. Articula uma temática pouco estudada no Brasil, através das construções teórico-conceituais mais usuais em outras áreas, principalmente as contribuições da sociologia, da antropologia e da economia. Finaliza desenvolvendo propostas de análise que incentivem estudos nos diferentes subáreas da geografia, dentre eles a Geografia Econômica, a Geografia do Turismo e a Geografia Cultural. Os paralelos entre o lazer e os diferentes ramos do conhecimento Geográfico culminam numa proposta esquemática de estudos entre Geografia e Lazer através da síntese das categorias e da proposta de um enquadramento teórico para cada uma delas. Conclui com ponderações a respeito do potencial e das 
limitações dos estudos na Geografia que possuam o lazer como objeto de estudo.

Palavras-chave: Turismo; enquadramento teórico; novas abordagens.

\begin{abstract}
Leisure activities became a human need and provide a myriad of meanings that can be read throughout space and time. As a social activity it consumes and develops in space and for individuals. In this article we intend to address the main similarities between tourism approaches, leisure and geography, by analyzing the theories, procedures and the nature of research. We portray the state of the art in top researches involving Leisure and Geography and searching for contributions in other areas. The theoretical framework is worked in the light of some of the most common geography concepts such as place, landscape and region, drawing opportunities of study for each concept. It articulates, through the most common theoretical-conceptual constructions in other areas, especially in the contributions of sociology, anthropology and economics. Part of the article is a series of proposals to encourage studies in different subfields of geography, including Economic Geography, Geography of Tourism and Cultural Geography. By drawing parallels between leisure and the different branches of Geographical knowledge, it culminates in a schematic proposal for studies of Geography and Leisure through the synthesis of categories and a theoretical framework proposal for each of them. It concludes with considerations about the potential and limitations of the studies in Geography having leisure as an object.
\end{abstract}

Key-words: Tourism; theoretical framework; new approaches.

\title{
1. INTRODUÇÃO
}

Ao longo dos anos, os estudos de lazer foram articulados em diversas áreas das ciências humanas, especialmente a Sociologia e a Antropologia (ROJEK 2010). Na Geografia, aproximações têm sido realizadas por meio do campo da Geografia do turismo da Geografia dos esportes. Neste artigo, procuraremos complementar tais análises por meio de uma sistematização de possíveis formas de abordagem do fenômeno lazer dentro de alguns conceitos geográficos.

O lazer, assim como qualquer outra atividade social, necessita de espaço. Terrenos baldios na periferia se tornam campinhos improvisados, festas juninas são realizadas em centros comunitários ou nos pátios de igrejas 
e escolas. Atividades esportivas por sua vez, podem recriar ambientes já consolidados no exterior das comunidades, mimetizando de forma intencional ou espontânea pistas de atletismo, quadras e campos esportivos.

Existem ainda espaços temporários de lazer, de uso perene, manifestas comumente nas ruas da periferia de centros urbanos. A forma, a hierarquia e 0 modo como se relacionam podem espelhar o progresso cultural de uma dada sociedade no tempo, seu modo de vida, suas expectativas e a herança cultural.

Por conta de sua pluralidade, é certo dizer que as atividades de lazer influenciam diretamente na ocupação e na (re)criação do espaço. Tal capacidade pode ser formalizada através de um espaço público, mantendo-se permeável através de práticas esporádicas ou fixas, podendo até ser praticadas dentro de um quarto, virtualmente através de um computador.

A adaptação destas atividades (regras, formatação, etc.) junto ao terreno e a sua multiplicidade e formas são características centrais na gênese e manutenção dos espaços por eles transformados.

No Brasil, encontramos grade parte da discussão a respeito diluída no campo da chamada Geografia dos esportes ${ }^{1}$ e nos estudos de turismo. Ademais, é quase impossível desassociar turismo de lazer, uma vez que se consolida como uma esfera possível de suas atividades e uma das mais importantes em termos de espaço produzido.

Este artigo procura elaborar um roteiro de pesquisa para os estudos de lazer e geografia, apontando procedimentos de estudo dentro das categorias consideradas importantes na ciência geográfica, como região, espaço e paisagem. Para tal, revisamos parte importante de teorias advindas de outras áreas, em especial a Sociologia e da Economia do lazer assim como das contribuições da Geografia do Turismo e da Geografia dos esportes. Ao fim foram elaboradas quatro propostas de abordagem e um esquema classificatório que viabilize o estudo de acordo com as características de cada atividade.

\footnotetext{
${ }^{1}$ Para maiores informações a respeito da Geografia dos Esportes ver Bale (2003) e Mascarenhas (1999, 2000, 2001).
} 


\subsection{Espaço, Lazer e tempo-livre: algumas definições}

No processo de análise do espaço têm-se como objetos de estudo as categorias de forma, função, processo e estrutura consagrados por Milton Santos na literatura (SANTOS, 2006). A utilização desta concepção permite estabelecer três tipos básicos de espaços de lazer: espaços concretos de lazer (forma física dominante, atividade específica), espaços temporários de lazer (ruas, campinhos, atividades temporárias) e espaços virtuais de lazer (ciberespaço). Para este trabalho utilizamos a consagrada definição de espaço de Milton Santos (2006, p.39):

[...] um sistema de objetos e um sistema de ações [...]: que é formado por um conjunto indissociável, solidário e também contraditório, de sistemas de objetos e sistemas de ações, não considerados isoladamente, mas como um quadro único na qual a história se dá.

Dada a natureza do significado, existem variações nos estudos de lazer que acaba influenciando em diferentes perspectivas. Na Geografia alemã, por exemplo, o Fremdenverkehr (turismo) possui estreitos laços com Rekreation (próximo a recreação). Em Inglês, muitos livros carregam a distinção proposital entre Leisure (lazer), Tourism (turismo) e recreation (recreação). Tais como George Torkildsen (2005) "Leisure and Recreation Management" e Contemporary Geographies of Leisure, Tourism and Mobility (2002) de Michael Hall. No entanto, os trabalhos desenvolvem-se em grande medida como uma subcategoria dos estudos relacionados ao Turismo. Na Geografia francesa, Languillon (2011) ressalta tais distinções:

Lazer é uma categoria não muito clara e sutil. Esta sutileza decorre em grande medida, pois a palavra muda de significado de acordo com sua ocorrência. No singular, lazer refere-se ao tempo liberto das exigências de tempo obrigatórias, especialmente do tempo trabalhado. Já no plural, torna-se recreação e refere-se a todas as atividades recreativas que atuem tanto no espaço local e hora do dia, no tempo e no turismo espacial. (LANGUILLON, 2011, adaptado). 
Ainda segundo o autor, a idéia de Turismo possui basicamente três elementos definidores: 1) O deslocamento do local cotidiano pela duração de mais de um dia; 2) Fuga do tempo cotidiano e desenvolvimento ou participação de um espaço-tempo especifico diferente do habitual; 3) Vivência diferenciada do tempo, caracterizada pela passagem do tempo comum (tempo de trabalho, obrigatório) para o tempo-distância (tempo de transporte) com o tempo de substância (saborear a passagem do tempo torna-se uma meta e um prazer em si).

Para a proposta deste trabalho tomaremos como base a definição de lazer de Joffre Dumazedier (1974) atêm-se fortemente as dimensões econômicas e sociais e a tomaremos como base para o desenvolvimento de nossos estudos:

\footnotetext{
(...) o lazer concerne a um conjunto mais ou menos estruturado de atividades com respeito às necessidades do corpo e do espirito dos interessados: lazeres físicos, práticos, artísticos, intelectuais, sociais, dentro dos limites do condicionamento econômico social, politico e cultural de cada sociedade. São a tais atividades que chamaremos de lazeres. Seu conjunto constitui o lazer. (DUMAZEDIER, 1974. p.92)
}

O tempo livre é aqui entendido como parte do lazer e não necessariamente condição sine qua non da existência de uma atividade lazer, e é sintetizado como aqueles momentos em que não há necessidade de trabalhar, ou qualquer outra atividade importante em termos de obrigação.

\subsection{A emergência do Lazer enquanto objeto de estudo}

O trabalho clássico de Thorsten Veblen, "Theory of the leisure class" publicado em 1899, abriu as portas para os estudos do papel que o lazer tem para a sociedade. Foi um dos primeiros a esquematizar o comportamento das classes operárias e seu uso do "tempo-livre". O autor procurou padrões sociais de comportamento do fenômeno entre homens e mulheres na Inglaterra Industrial do séc. XVII. 
De acordo com Rojek (2010, p.44-50), o estudo de lazer é permeado por tradições de pesquisa, centradas em temas como: gênero (vertentes influenciadas pelo feminismo), classes (sobre influência do marxismo), do formalismo social (considerada de viés positivista), na sociologia figurativa (envolve processos, redes) e nas vertentes pós-estruturalistas mais recentes.

Grande parte do interesse pelo estudo do lazer enquanto fenômeno vem no esteio da promoção de comuns nas primeiras décadas do séc.XX. Transformariam o lema romano mente sana corpore sano em mentalidades públicas como nos estudos de Daley (2003). Como conseqüência, houve o desenvolvimento e o aprimoramento de uma política de construção de equipamentos dedicados a utilização do lazer em consoante com o desenvolvimento pessoal e o ideário de uma nação saudável (idem, ibidem).

Nesta época há uma proliferação de edificações ligadas ao lazer no Brasil, tais como: estádios de futebol, passeios públicos, clubes de regatas, parques e campos de esporte espalhados pelas cidades. Construções relacionadas com lazer possuem a capacidade de carregarem tanto na concepção quanto na forma final, aspectos simbólicos, camadas de tempo e ideologia.

Dentro da tradição espanhola, a geografia do lazer encontra-se mais consolidada. O termo Geografia del Ocio presentes nos trabalhos de Quintana e Nebreda (2010) por exemplo, estão diretamente ligados à porção do tempo livre, encontrando em grande medida, semelhança com o conceito de Dumazedier.

Já nos trabalhos de tradição anglo-saxã como em Rojek (2010) e Torkildsen (2005), as características únicas das atividades tomam rumos próprios, não existindo redundância em chamar uma subcategoria do lazer de recreação ou de turismo, mesmo que habitem diferenças nas concepções dos autores. 
Na França sobressaem os trabalhos de Georges Cazes (RICHEZ, 1993), a partir de sua obra "Pour une géographie du tourisme et des loisirs" (1992) abre um novo campo de estudo e é considerado um pioneiro em seu país. Concentram-se nos seguintes temas: a recreação ao ar livre, grandes parques temáticos, centros comerciais, parques aquáticos e áreas de encontros em centros urbanos.

$\mathrm{Na}$ Geografia alemã, o lazer configura um objeto de estudo dentro da Geografia do Turismo. JURCZEK (1981) argumenta que a introdução de uma abordagem sócio-geográfica e comportamental a partir da década de 1960 . Ambos os objetos de estudo são retratados em conjunto numa disciplina de Geografia do Lazer e Turismo (Geographie der Freizeit und des Tourismus). Como veremos na seção seguinte, é nesta tradição que aparecem as principais propostas de estudo sistemático do assunto, como no modelo de Bruno Benthien (Fig.1) ou na abordagem clássica de lugares centrais propostas por Walter Christaller (1955).

Por fim, em defesa de múltiplas abordagens no estudo do lazer, Daley (2003) advoga a defesa do que ele chama de "equilíbrio múltiplo", entendendo o ecletismo como algo positivo à progressão dos estudos do lazer. Sendo assim, e em concordância com o autor, iremos propor nesta pesquisa como 0 lazer enquanto fenômeno espacial a fim de delinear os principais meios de compreensão utilizando-se de diferentes tradições e escolas da Geografia que irão compor os exemplos e as propostas de estudo deste artigo.

\subsection{Propostas de abordagem para a Geografia}

Um tratamento geográfico da temática do lazer exige primeiramente uma abordagem espacial do conjunto de atividades ligadas direta ou indiretamente à atividade. Das principais formulações podemos citar o trabalho do geógrafo alemão Bruno Benthien (1984). Seu esquema clássico de análise é assim condensado: 
A. Necessidades Sociais

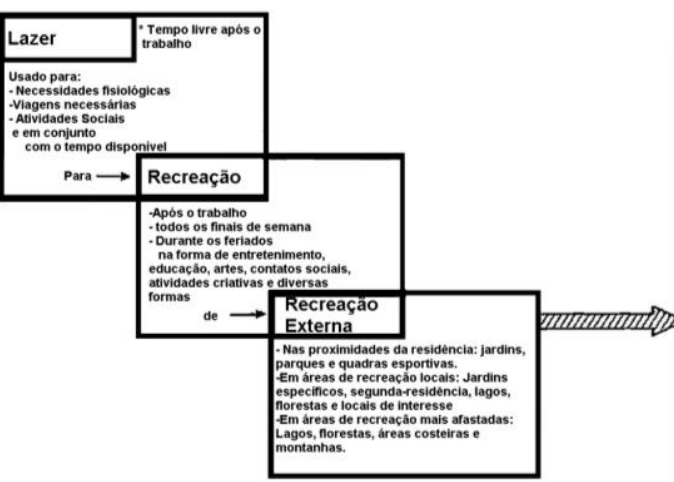

B. Modelo básico: Sistema de recreação territorial (TRS)

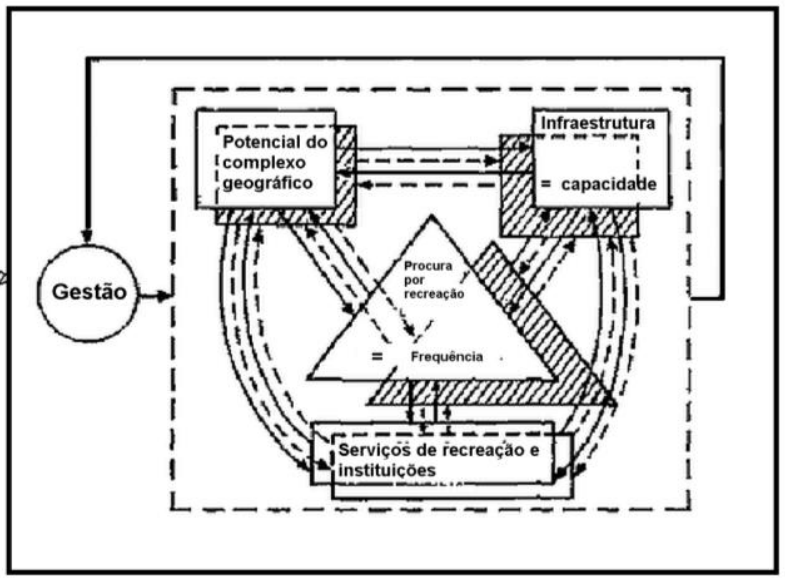

Fig.01 Esquema clássico de Benthien para a Recreational Geography Fonte: Benthien (1984, p.3). Traduzido e adaptado pelos autores. Foco na demanda e funcionalidade dos espaços. $O$ autor procura algumas mediações socioculturais, mas sem grande aprofundamento.

Embora a abordagem esteja quase que exclusivamente centrada no território e no planejamento, sua qualidade reside na diferenciação e nos princípios gerais de causalidade entre demanda por lazer e obtenção. Seu esquema inicial pode servir como base para análise, inventário e documentação, dentre as suas mais variadas formas de distribuição das categorias de análise na geografia.

Assim como no turismo, sua construção não se dá somente no campo bidimensional, mensurável através de teorias econômicas. Os campos afetivo e simbólico apontam para uma racionalidade, nem sempre linear, variando temporalmente.

Ao procurarmos uma conceituação mais adequada para aquele que é o nosso objeto de estudo principal, percorreremos o caminho sociológico traçado por um dos principais teóricos da Sociologia do lazer: Joffre Dumazedier (19152012).

O autor não traz em si uma aplicação "geográfica", uma vez que esta não é sua principal preocupação. No entanto realiza ponderações a respeito do espaço urbano, mas sem aprofundar em uma teoria espacial específica. Sua 
consideração a respeito do espaço do lazer aproxima-a da cultura. Afirma, por exemplo, que "O espaço do lazer, tanto quanto o espaço cultural, é um espaço social onde se estabelecem relações específicas entre seres, grupos, meios e classes". (DUMAZEDIER, 1974. P.169).

Em "Sociologia Empírica do Lazer" (1974), Dumazedier traça alguns objetivos e metodologias. Procurou-se aqui, portanto, trabalhar alguns de seus postulados com a prática do lazer em sua dimensão espacial. Para isto, propõe quatro definições básicas necessárias, que tornam o lazer um objeto de estudo dentro da sociologia, sobre a qual nos espelhamos para a pesquisa em geografia. Assim é definido o corpo estrutural de sua interpretação:

\section{1) Forma e periodicidade}

Primeiramente, no que tange a questão lógica, deve o objeto ser diferençável de outros do mesmo gênero, por uma diferença específica que seja a menos ambígua possível. Para isso, devemos estudá-lo dentro de sua manifestação espacial, como formas e periodicidade.

2) Fatores determinantes

Em segundo lugar, aparece a questão da validade em relação aos problemas maiores da Sociedade. É neste sentido que se investiga o conjunto de fatores que definem o "uso" do tempo livre.

3) Transformação resultante da ação humana

Em terceiro lugar, deve esforçar-se para operar de acordo com os comportamentos sociais correspondentes. Ou seja: expectativas, vivências e períodos aparecem como motrizes da transformação resultante da ação humana em espaços de lazer.

4) Levar em conta a divisão do trabalho 
Por último, deve-se ter igualmente em conta a divisão do trabalho existente na sociedade, levando em consideração os diferentes ramos especializados, tais como trabalho, politica, entre outros.

\subsection{Viagem/Paisagem como outdoor recreation (recreação a céu aberto)}

Ainda seguindo as categorias de Benthien (1984), a necessidade de locomoção visando o benefício do lazer se faz a partir de um conjunto de características inerentes a determinadas Paisagens. Possui estreita relação com a atividade turística. Pode-se neste ínterim, recorrer a uma agência de viagens, a uma segunda residência, e, na maioria dos casos, a grandes levas de imigração, especialmente nas datas oficiais de descanso.

As características de atração/repulsão de uma determinada localidade são amplamente conhecidas. Disponibilidade de infraestrutura, atrativos turísticos, hospitalidade, preços dentre outros. O que procuramos traçar como diferencial e ramo disponível da pesquisa são as características específicas que fazem uma Paisagem "atrativa" do ponto de vista cênico, por exemplo.

Os componentes de uma Paisagem, seus atributos e a capacidade relativa de mediar sensações são mapeáveis a partir de determinadas metodologias, tais como a Geografia da Percepção em Yi-fu Tuan (2013, 2012) ou os sistemas de catálogo sistemático de preferências visuais como em Scenic Solutions (2009).

\subsection{Lazer enquanto atividade ordenadora}

Por ser adaptável, o lazer pode ocupar temporalmente e espacialmente uma dada localidade ${ }^{2}$ sem, no entanto, tornar-se visivelmente permanente. Existem basicamente três grupos de espaços ordenados por meio do lazer. Lembrando que, um mesmo grupo pode estar associado a várias interações em um mesmo local.

Grande parte da atenção foi focada na questão dos espaços livres urbanos (ARANHA-SILVA 2004). Enquanto áreas importantes no fornecimento

\footnotetext{
${ }^{2}$ Sobre a qualidade de espaços e equipamentos de lazer ver STUCCHI (1997).
} 
do lazer, ao mesmo tempo em que atende as necessidades das comunidades em suas cercanias.

Equipamentos de Lazer: Alguns exemplos de interações

\begin{tabular}{ll}
\hline Tipo & Associado a \\
\hline Gastronômico e social & Bares, botecos e restaurantes \\
Fuga do cotidiano & Paisagens, lugares distantes \\
Identidade coletiva, imaginário social & Espaços públicos ou privados \\
Identidade étnica, reforço e continuidade & Local simbólico, datas comemorativas \\
Identidade religiosa & Locais sagrados, trajetos e datas comemorativas \\
Ciberlazer & Lan-house ou cômodos \\
\hline
\end{tabular}

Tabela 1- Equipamentos de Lazer: Alguns exemplos de interações.

O primeiro grupo conta com espaços diretamente transformados pela atividade. Portanto são pouco permeáveis, tais como, centros poliesportivos ou campos de esportes. São criados especificamente para estas finalidades. Uma vez que possuem um caráter mais "oficial", o mapeamento de suas funções e evolução é facilitado por meio de registros oficiais.

Num segundo grupo, estão presentes aqueles que se desenvolvem pela prática e vão ganhando espaço próprio com o tempo. Seu estudo e mapeamento são mais difíceis, pois envolvem diferentes períodos históricos e dados não oficiais.

No ultimo grupo, por sua vez, encontramos as realizações temporárias como festas, competições de rua ou parques. Ganham significado pela prática e nem sempre constituem espaço próprio. 


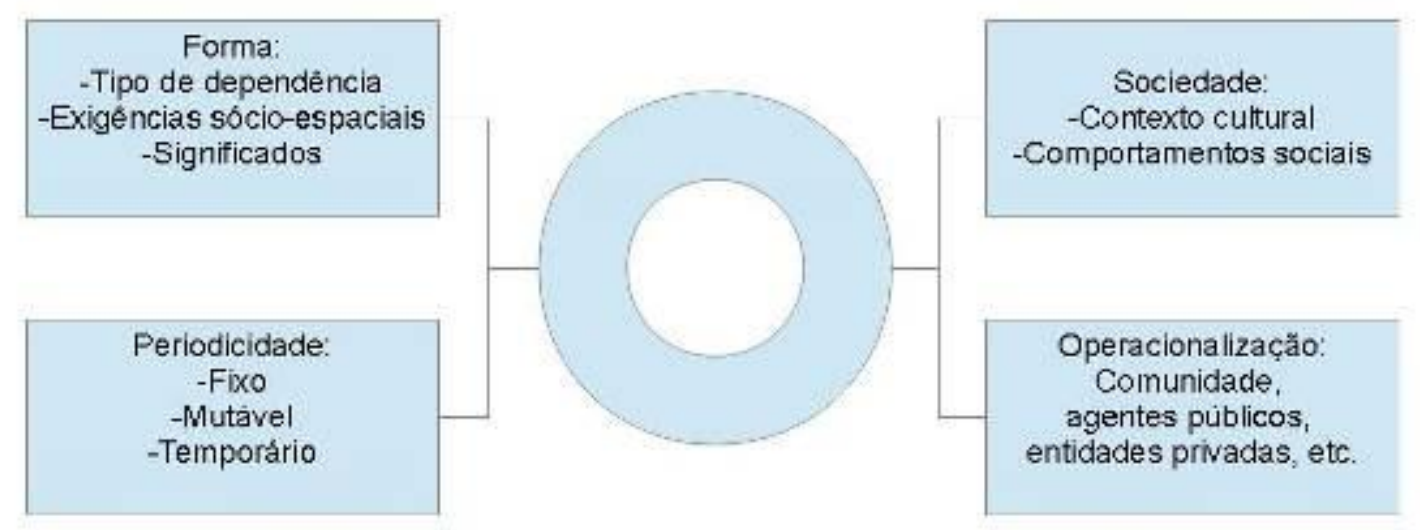

Fig.02- Equipamentos de Lazer na Cidade: Leituras Possíveis.

\subsection{Teoria das localidades centrais e o lazer.}

Nas abordagens de cunho regionalista, temos uma forte preocupação socioeconômica, fundadas principalmente em questões de oferta e demanda. Os estudos econométricos, calculam população atingida e potencial para consumo, com foco no papel do planejamento urbano.

Entende-se por localidades centrais, os lugares que se distinguem em relação aos demais e, mantem com estes, interações por meio de fluxos, constituindo as centralidades. Como destaca Corrêa (2000), a teoria das localidades centrais: "(...) aborda a organização espacial desses lugares, organização que inclui a hierarquia entre eles" (p.37, adaptado). Sendo assim, os equipamentos urbanos ligados à prática do lazer são exemplos desta centralidade.

Com base neste conceito, e amparado pelas formulações de Bale (2003, p.58), a teoria das localidades esportivas pode vir ser concebido como um modelo normativo. Ou seja, desde que sejam assumidas "certas suposições embutidas" (Idem, ibidem). Resume-se basicamente a cinco aspectos: 
1. A principal função de uma localidade é a de abastecer hinterlândias adjacentes de produtos relacionados ao lazer. Sendo assim, tendem a se localizar próximos a seus mercados.

2. Quanto maior o número de lazeres fornecidos, maior será a sua ordem dentro das localidades esportivas.

3. Localidades que ocupem escalas mais baixas fornecem infraestruturas de lazer que são utilizadas por pequenas áreas de captação; a população pioneira necessária para tornar o lazer viável é pequena.

4. Localidades que ocupam escalas maiores estão em menor número são mais espaçadas e possuem uma população inicial muito maior.

5. Uma hierarquia entre as localidades de lazer existe de maneira a tornar - mais eficiente possível o arranjo de oportunidades para (a) consumidores que visam minimizar suas viagens a fim de obter 0 esporte que desejam e (b) produtores do esporte que necessitam de uma demanda mínima a fim de sobreviverem.

Acerca das teorias de difusão das inovações, têm-se, de acordo com Claval (2007, p. 160-163), dois tipos principais de difusão: a hierárquica (rede de cidades e lugares) e de proximidade (localidades próximas, vizinhança) catalogadas nos trabalhos clássico do sueco Torsten Hagërstrand. De acordo com Lima (2004, p.76) apud Giron e Amorin, (2007) o fenômeno de difusão:

(...) revela-se como um fenômeno de propagação social das atividades produtivas ou de outras transformações que ocorrem no espaço e no tempo. Neste processo de difusão deve existir "um centro emissor", a região-pólo ou uma cidade, e "um centro receptor", ou seja, a periferia. Porém, essa periferia deverá ser capaz de absorver o produto dessa difusão. (idem, p.76)

\subsection{Lazer e lugar}

Fazendo uma rápida abstração, podemos verificar que, muitos terrenos baldios ganham significado a partir do momento em que se fincam duas traves de madeira ou dois chinelos, por exemplo. Em uma escala diferente, os tradicionais fenômenos tipicamente econômicos de push and pull (atração e 
repulsão das atividades) são acionados, atraindo participantes e delimitando o território através do lazer.

Alguns estudos apontam para as dimensões micro espaciais do lazer. Os chamados lazeres de pequeno porte, como os botequins, que possuem uma capacidade de distribuição espacial comum à paisagem urbana nacional (ADÃO 1999). Dentro de nossa classificação (Tab.01), consideramos o "boteco" também como um equipamento de lazer, pois incorpora o tempo-livre, perfazendo assim um espaço tradicional e persistente de lazer.

Bale (2003) se apodera da metáfora de Yi Fu-Tuan, quando vê o jardim como uma versão botânica do animal ao exemplificar como as Sportscapes podem por sua vez fazer uso deste expediente. Como num Jardim, as expressões materiais do Lazer possuem elementos naturais e não naturais. Construções ou espaços que compõem significados, em uma relação de dominância e incorporação, mesmo que temporária por parte dos humanos ${ }^{3}$.

\footnotetext{
${ }^{3} \mathrm{Em}$ um jardim, a água é controlada na forma de fontes, cursos d'água artificiais e cachoeiras. A dominação humana sobre a água é vista nos esportes, cursos artificiais para a canoagem, caiaques, são alguns exemplo. Na natação controla-se a água de uma maneira tipicamente moderna. Nos dizeres do escritor Joan Didion, “(...) a piscina de natação é, para muitos de nós ocidentais, um símbolo não de afluência, mas de ordem, de controle sobre o incontrolável (...)" (BALE 2003).
} 


\section{Estruturação de lazer público e privado: Fases de consolidação e implementação}

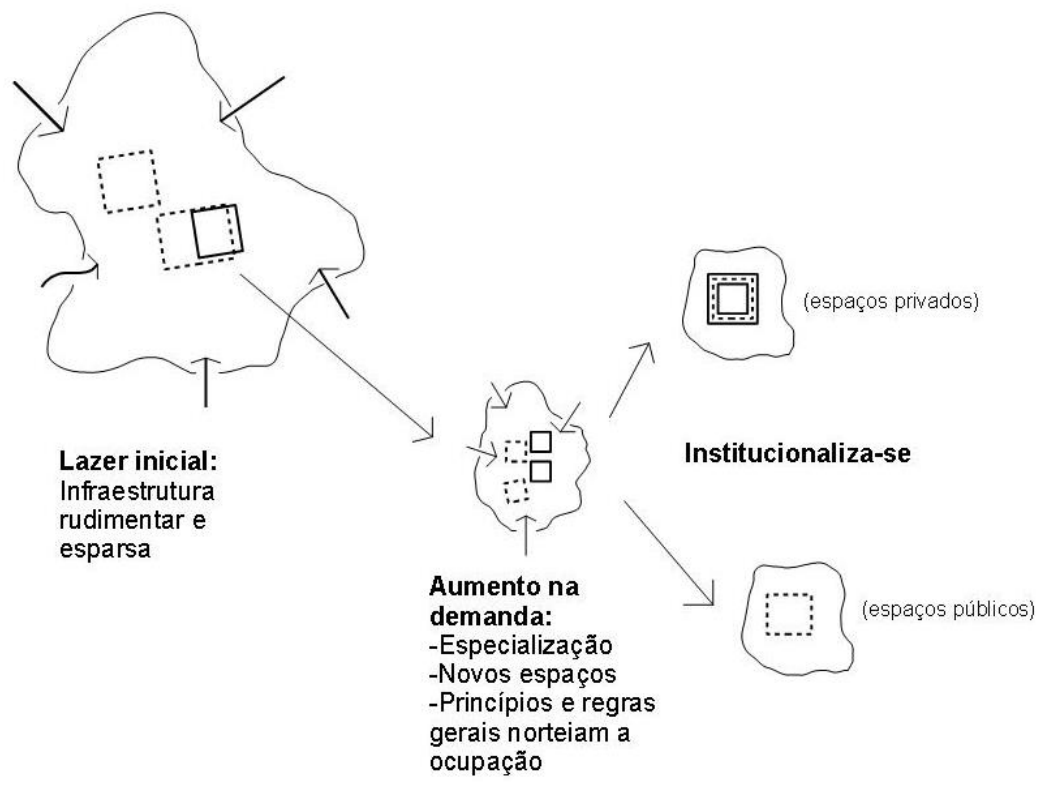

Fig.03- Esboço representacional do comportamento da estruturação de lazer e de lugar.

\subsection{Geografia e lazer: Esquema classificatório.}

O lazer no espectro sociológico de Dumazedier possui um conjunto próprio de caracteres específico tais como: liberatório, desinteressados, hedonístico e pessoal. Cada um destes caracteres específicos possui um correspondente físico para sua prática. Somos diretamente afetados pelo caráter liberatório e pelo caráter pessoal de certo gênero de obrigações que são condicionadas pelos fatos e determinações sociais.

No âmbito pessoal, o lazer pode surgir enquanto resposta a obrigações primárias impostas pela Sociedade. São utilizadas basicamente da seguinte forma (IWANOWICZ, 1997, p.94): (1) enfraquecimento do individuo (por meio de vícios, como o alcoolismo p.ex.); (2) recuperação (propiciando ao indivíduo a oportunidade de se livrar da fadiga psicológica ou física, do tédio, de tarefas repetitivas) (3) como fuga de rotina e estereótipos.

Para o autor, o lazer mais completo é aquele que melhor equaciona estes aspectos, tornando a experiência a mais satisfatória possível. É possível 
elaborar esquemas de compreensão das motivações e aspectos geográficos destas atividades, tais como difusão e apropriação do espaço.

Lazer e Geografia: exigências sócio-espaciais e separação por categorias de análise

\begin{tabular}{|c|c|c|c|c|}
\hline Local & Ambiente & Manifestação & Público Alvo & Renda \\
\hline$\nabla$ & $\nabla$ & $\nabla$ & $\nabla$ & $\nabla$ \\
\hline $\begin{array}{l}\text { O local da prática } \\
\text { do lazer pode } \\
\text { variar } \\
\text { culturalmente. } \\
\text { Aqui } \\
\text { consideramos as } \\
\text { dimensões do seu } \\
\text { ponto de vista de } \\
\text { funcionalidade e } \\
\text { disposição de } \\
\text { recursos, assim } \\
\text { como dos } \\
\text { significados } \\
\text { decorrentes. A } \\
\text { estrutura do local } \\
\text { é importante } \\
\text { componente no } \\
\text { estudo da } \\
\text { paisagem. Sejam } \\
\text { em estádios, nas } \\
\text { ruas ou em bares } \\
\text { de esquina. }\end{array}$ & $\begin{array}{l}\text { Tipo de ambiente, } \\
\text { se é aberto ou } \\
\text { fechado. Se pode } \\
\text { ser visto com } \\
\text { facilidade pela } \\
\text { comunidade } \\
\text { exterior, ou se é } \\
\text { fechado em certos } \\
\text { grupos étnicos ou } \\
\text { sociais. }\end{array}$ & $\begin{array}{l}\text { Questão da } \\
\text { manifestação em } \\
\text { si (no momento } \\
\text { em que ocorre). } \\
\text { Significados } \\
\text { recorrentes das } \\
\text { atividades no } \\
\text { espaço } \\
\text { transformado. A } \\
\text { geografia cultural } \\
\text { tem grande } \\
\text { potencial neste } \\
\text { subcampo. De } \\
\text { festas juninas de } \\
\text { rua às tradicionais } \\
\text { corridas } \\
\text { esportivas. O } \\
\text { footing foi e ainda } \\
\text { é um componente } \\
\text { importante nas } \\
\text { praças. As } \\
\text { manifestações } \\
\text { possuem } \\
\text { diferentes } \\
\text { temporaliedades }\end{array}$ & $\begin{array}{l}\text { Diz respeito à } \\
\text { faixa etária, à } \\
\text { classe social, } \\
\text { etnia, gênero, } \\
\text { grupo e faixa } \\
\text { etária. Existem } \\
\text { diferen ̧̧as e } \\
\text { graduações. P.ex. } \\
\text { Grupos de jovens } \\
\text { que demandam } \\
\text { espaços abertos } \\
\text { para a prática de } \\
\text { esportes radicais e } \\
\text { grupos de jovens } \\
\text { que utilizam jogos } \\
\text { eletrônicos. Com } \\
\text { atividades } \\
\text { geralmente } \\
\text { realizadas no } \\
\text { contra-tumo } \\
\text { escolar. }\end{array}$ & $\begin{array}{l}\text { Alguns tipos de } \\
\text { lazer estão } \\
\text { diretamente } \\
\text { relacionados à } \\
\text { determinadas } \\
\text { faixas de renda, } \\
\text { enquanto outros } \\
\text { são universais. A } \\
\text { renda neste } \\
\text { subitem pode ser } \\
\text { avaliado como } \\
\text { um fator } \\
\text { condicionante ao } \\
\text { acesso. A } \\
\text { geografia } \\
\text { ecônomica } \\
\text { encontra grande } \\
\text { fertilidade neste } \\
\text { campo. }\end{array}$ \\
\hline
\end{tabular}

Figura 4- Exigências sócio-espaciais e suas conexões com a Geografia. Definição esquemática e classificação.

\section{CONSIDERAÇÕES FINAIS}

O mapeamento da evolução dos espaços de lazer é uma das maneiras de se compreender a própria evolução e transformação. O lazer não é único e essencialmente urbano, mas é parte importante da urbanidade.

Uma classificação de formas de manifestação, com ênfase no planejamento de espaços dedicados ao lazer, tem como papel, clarificar usos passados e tradições que podem servir para a continuidade daquele espaço. Muitos projetos realizados à revelia dos anseios reais de uma comunidade se degeneram rapidamente. 
Devido à sua natureza eminentemente diversificada, o fenômeno do lazer espelha preferências humanas nas mais variadas formas de manifestação. O lazer "oficial" é facilmente captável através de estudos regionais, auxiliados em grande parte pelos conceitos como oferta e demanda. O espaço geográfico do lazer encontra manifestação enquanto atividade ordenadora, tornando passível uma leitura a partir da distribuição de suas localidades (incorporando em grande medida a teoria das localidades centrais) e as relações mediadas pelos diferentes agentes produtores envolvidos na produção do espaço.

Já a influência de tais atividades na categoria de "lugar", exige uma compreensão mais aguçada dos fenômenos que cercam todo o contexto no qual está inserido, abrigando-se fortemente nos conceitos da sociologia do lazer. A paisagem vista como outdoor recreation é central enquanto qualidade cênica. Paisagens atrativas podem evocar uma noção de descanso ou de aventura. Essa característica de atratividade/repulsa configura eixo central de análise.

Neste artigo nos detivemos em grande medida às dimensões de manifestação concreta das atividades de lazer, utilizando-se das contribuições do turismo e dos estudos envolvendo Geografia e lazer existentes na Alemanha, na França e em países anglo-saxões.

Existe amplo espaço para a discussão da dimensão simbólica das relações entre Geografia e lazer, abordadas de forma sutil neste trabalho. Outras propostas de abordagem podem surgir de outras contribuições teóricas, como aquelas advindas da fenomenologia.

\section{REFERÊNCIAS BIBLIOGRÁFICAS}

ADÃO, K. O Botequim e a geografia do ócio na Paisagem compartimentada da cidade. Revista Conexões. Campinas, ํo3, p.92-102. 1999. 
ALDAY, A.M. Economia del ócio in: CABEZA, C. M (org.). Aproximacion Multidisciplinar a los estúdios de Ocio. Documentos de estúdios de Ocio n. 31. Bilbao: Editora Universidad de Deusto 2006. Cap.3, p.45-74.

ARANHA-SILVA, E. Lazer nos espaços urbanos. Revista Eletrônica da Associação dos Geógrafos Brasileiros, Seção Três Lagoas, Três LagoasMS, v. 1, n.1, p. 54-68, 2004

AUSSEL, R. Tourisme et loisir(s), pour une brève définition. Géoconfluences, Lyon, n. especial: "Environnenment, ville, société", fevereiro 2011.

BALE, J.R. Sports Geography. Londres: Routledge, 2003.

BENTHIEN, B.: Recreational Geography in the German Democratic Republic. GeoJournal, Ohio. vol.9 jan., p. 59-63.1984

CHRISTALLER, W. Beiträge zu einer Geographie des Fredenverkehrs. Erdkunde, Berlim, v. 9, fevereiro 1955.

CORRÊA, R. L. Região e Organização Espacial. São Paulo: Ática. 2000.

DALEY, C. Leisure \& Pleasure Reshaping \&Revealing the New Zealand Body: 1900-1960. Auckland: Auckland University Press, 2003.

DUMAZEDIER, Joffre. Sociologia empírica do lazer. São Paulo: Perspectiva, 1974.

HALL. C.M. PAGE, C.M. The Geography of Tourism and Recreation: Environment, Place and Space. 2ํe ed. Nova York e Londres: Routledge, 2002.

IWANOWICZ, J.B. Aspectos Psicológicos do Lazer in: BRUHNS, T.H. Introdução aos estudos do Lazer. Campinas: Editora da Unicamp, 1997 Cap.7. p.83-104.

JURCZEK, P. Freizeit, Fremdenverkehr und Naherholung. Práxis Geographie, Sttutgart, v. 11, p. 45-49, 1981. 
MASCARENHAS, G. A Geografia e os esportes: uma pequena agenda e amplos horizontes. Conexões. Campinas, v. 1/2, p. 46-59, 1999.

.A dimensão espacial dos esportes. Revista Biblio 3w (Barcelona), Barcelona, v. 208, sem página, 2000. .Considerações teórico-metodológicas sobre a difusão espacial do futebol. Geo UERJ, Rio de Janeiro, v. 10, p. 73-82, 2001.

QUINTANA, I.I; NEBREDA, D. J (org.). Espacio y experiência de ócio: consolidacion, transformacion y virtualidade. Bilbao: Universidad de Deusto, 2010.

RICHARDS, G.; ZSUZSANNA, T. Leisure clusters: From Theory to practice. Tiburg: Tiburg University press, 2012.

RICHEZ, G. Pour une géographie du tourisme et des loisirs: Georges Cazes (1992). Méditerranée, Aix-en-Provence, v. 78, n. 3, p. 107-109, 1993.

ROJEK, C. The Labour of Leisure: The Culture of free time. California: SAGE, 2010.

SANTOS, S. A Natureza do Espaço: Técnica e Tempo, Razão e Emoção. São Paulo: EDUSP, 2006.

SCENIC SOLUTIONS. Findings of international landscape studies landscape preferences. Melbourne, 2009. Disponível em:

http://www.scenicsolutions.com.au/Int\%20studies\%20preferences.html acesso em 5 de outubro de 2014.

STUCCHI, S. Espaços e equipamentos de recreação e lazer in: in: BRUHNS, T.H. Introdução aos estudos do Lazer. Campinas: Editora da Unicamp, 1997 Cap.8 .p.105-121.

VEBLEN, T. The Theory of the Leisure Class. S/Local. Project Gutenberg: 2008 [1899]. 